\title{
Artemisinin and Quinoline Hybrid Compounds Inhibit Replication of SARS-CoV-2 In Vitro
}

\author{
Lars Herrmann, ${ }^{[a]}$ Ivan A. Yaremenko, ${ }^{[b]}$ Aysun Çapcı, ${ }^{[a]}$ Julia Struwe, ${ }^{[c]}$ Jan Hodek, ${ }^{[d]}$ \\ Yulia Yu. Belyakova, ${ }^{[b]}$ Peter S. Radulov, ${ }^{[b]}$ Grigoriy A. Stepanov, ${ }^{[\mathrm{e}]}$ Jan Weber, ${ }^{[\mathrm{d}]}$ \\ Alexander O. Terent'ev, ${ }^{*[b]}$ Lutz Ackermann, ${ }^{*[,, f]}$ and Svetlana B. Tsogoeva*[a]
}

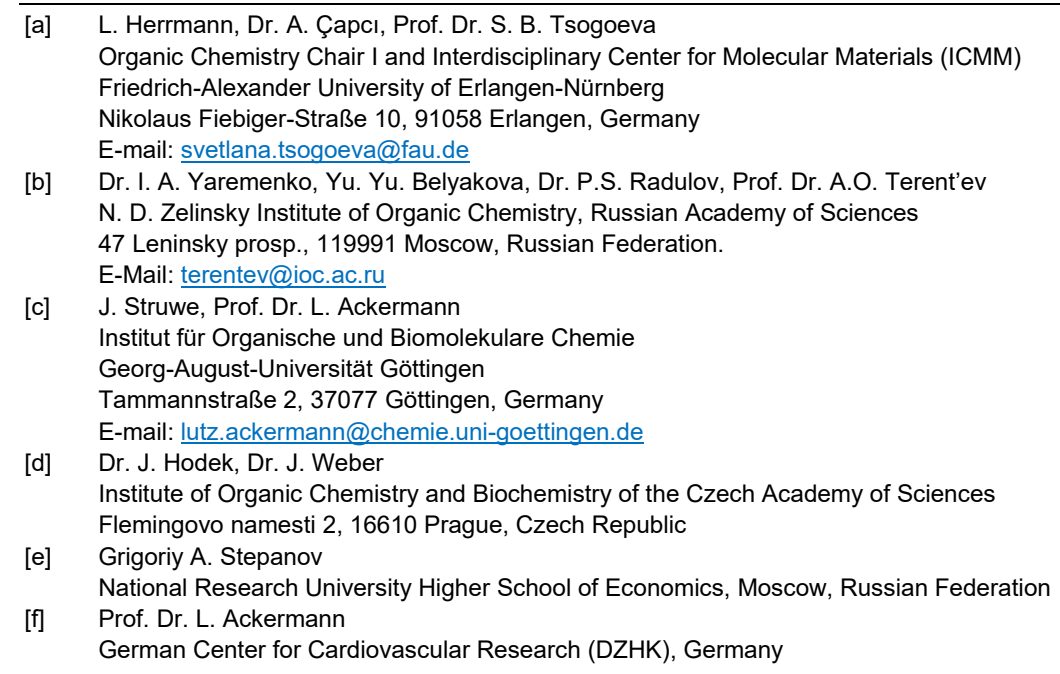

\begin{abstract}
The newly emerged severe acute respiratory syndrome coronavirus 2 (SARS-CoV-2) cause life-threatening diseases in millions of people worldwide and there is an urgent need for antiviral agents against this infection. While in vitro activities of artemisinins (containing endoperoxide moiety) and chloroquine (containing quinoline subunit) against SARS-CoV-2 have recently been demonstrated, no study of artemisinin- and quinoline-based hybrids has been reported yet. However, the hybrid drug's properties can be improved compared to its parent compounds and effective new agents can be obtained by modification/hybridization of existing drugs. In this study, fifteen artemisinin- and quinoline-containing hybrid compounds were synthesized and analyzed in vitro for the first time for their inhibitory activity against SARS-CoV-2 in a cytopathic effect reduction assay. All artesunic acid-containing hybrids display superior potency against SARS-CoV-2 $\left(\mathrm{EC}_{50}\right.$ values $\left.7.8-46 \mu \mathrm{M}\right)$ and show low or no cytotoxic effects on Vero E6 cells $\left(\mathrm{CC}_{50}\right.$ up to $\left.110 \mu \mathrm{M}\right)$. The most active artesunic acid-derived hybrid is significantly more potent in vitro $\left(\mathrm{EC}_{50}=7.8 \mu \mathrm{M}\right)$ than its parent compound artesunic acid $\left(E_{50}>50 \mu \mathrm{M}\right)$. Among quinoline-based new compounds, quinoline-adamantane $\left(\mathrm{EC}_{50}=1.5 \mu \mathrm{M}\right)$ is the most efficient in vitro outperforming the reference drugs chloroquine $\left(\mathrm{EC}_{50}=3.8 \mu \mathrm{M}\right)$ and remdesivir $\left(\mathrm{EC}_{50}=4.0 \mu \mathrm{M}\right)$.
\end{abstract}

\section{Introduction}

The novel human infection with the severe acute respiratory syndrome coronavirus type 2 (SARS-CoV-2) is spreading rapidly across the world since it was first identified at the end of 2019. It is highly contagious and leads to serious disease COVID-19 (coronavirus disease 2019), which was declared as a pandemic by the World Health Organization (WHO) on March 11th 2020. ${ }^{[1]}$ Several types of vaccines have already been developed, whereas effective antiviral treatments are lacking. Hence, development of novel efficient drugs against SARS-CoV-2 is highly desired.

One of the most frequent approaches is repurposing drugs already licensed for other diseases. While known repurposed drug Remdesivir (RDV) (Figure 1, A) showed activity in vitro against SARS-CoV-2 ${ }^{[2]}$ and was first approved by the FDA for the use against SARS-CoV-2, there were insufficient clinical studies and since recently, due to low efficiency, its use for the treatment of COVID-19 is no longer recommended. ${ }^{[3]}$ Also chloroquine and hydroxychloroquine (Figure 1, A) - two antimalarial drugs that are active against several viruses, ${ }^{[4]}$ including HIV, hepatitis $\mathrm{C}$ and Ebola - were reported to be active against SARS-CoV-2. ${ }^{[2,5]}$ These two drugs - both containing a quinoline subunit, showed high potency against SARS-CoV-2 - but neither in vitro studies nor clinical trials gave results consistent enough either in single use or in combination with other drugs like lopinavir or ritonavir. ${ }^{[2}$ $5 b, 6]$

Recent studies demonstrated, that cyclic synthetic peroxides exhibit antiparasitic, ${ }^{[7]}$ anticancer ${ }^{[8]}$, antifungal, ${ }^{[7 e, 9]}$ antitubercular ${ }^{[10]}$ and antiviral[ ${ }^{[11]}$ activities. Notably, synthetic peroxide arterolane (Figure 1, B), used in medical practice for treatment of malaria, ${ }^{[12]}$ has recently also been characterized for it's in vitro activity against $\alpha$-coronavirus NL63, $\beta$-coronaviruses OC43 and SARS-CoV-2. ${ }^{[13]}$

Recently, it has been shown that plant extracts from Artemisia annua, which contain artemisinin - a sesquiterpene lactone with peroxide bridge, and used in traditional medicine as antimalarial drug, exhibit anti-viral activity against SARS-CoV2 in vitro. ${ }^{[14]}$ These findings back the hypothesis, that African 
countries have been hit later and weaker by the pandemic than expected, due to widespread use of artemisinin based traditional antimalarial medicine or artemisinin-based combination therapy (ACT). ${ }^{[15]}$ The anti-SARS-CoV-2 potential of artemisinins (Figure $1, \mathrm{C})$ was also determined in a pharmacokinetic model in vitro. ${ }^{[16]}$ Notably, artesunic acid, the API (active pharmaceutical ingredient) in FDA-approved malaria treatments, was demonstrated to show high in vitro potency against SARS-CoV$2 \cdot{ }^{[16 b]}$

Despite these promising results, the WHO still advises to use artemisinins in ACT to prevent the development of drug resistances. The use of artemisinins is mainly focused on regions, where they are also applied for malaria treatment. In these regions, the risk is high that resistant malaria strains will spread due to use of artemisinins against SARS-CoV-2. ${ }^{[14]}$ Besides ACT, another powerful strategy to combat the emergence of drug resistances against artemisinins, is the use of hybrid molecules, which have been shown to not only prevent the development of new resistances, but also to have the ability to overcome these. ${ }^{[17}$, ${ }^{18]}$ Furthermore, an improvement of anti-SARS-CoV-2 efficacy of artemisinins through their hybridization with selected bioactive compounds is also expected. Thus, as alternatives to already studied known drugs, our ongoing quest for active hybrid molecules, which exceed their parent compounds in terms of activity against SARS-CoV-2, motivated the synthesis of new artemisinin- and quinoline-containing hybrid compounds 1-15 (Figure 2). Therefore, we set out to determine for the first time whether hybrids of artesunic acid and quinoline might be even more efficient against SARS-CoV-2 in vitro, in comparison to their already active parent compounds.

In the present study, we demonstrate that these new hybrid compounds are indeed highly efficacious in cultured-cell-based SARS-CoV-2 models. The most active artesunic acid-derived hybrid $7\left(\mathrm{EC}_{50}=7.8 \mu \mathrm{M}\right)$ is, e.g., significantly more potent in vitro than its parent compound artesunic acid $\left(E_{50}>50 \mu \mathrm{M}\right)$. Among the quinoline-based hybrids, quinoline-adamantane $15\left(\mathrm{EC}_{50}=\right.$ $1.5 \mu \mathrm{M})$ is the most efficient agent in vitro, outperforming both reference drugs chloroquine $\left(\mathrm{EC}_{50}=3.8 \mu \mathrm{M}\right)$ and remdesivir $\left(\mathrm{EC}_{50}\right.$ $=4.0 \mu \mathrm{M})$. Remarkably, the new hybrid compounds show low or no cytotoxic effects on Vero E6 cells $\left(\mathrm{CC}_{50}\right.$ up to $\left.110 \mu \mathrm{M}\right)$, which are used as a model for SARS-CoV-2 susceptible cells.

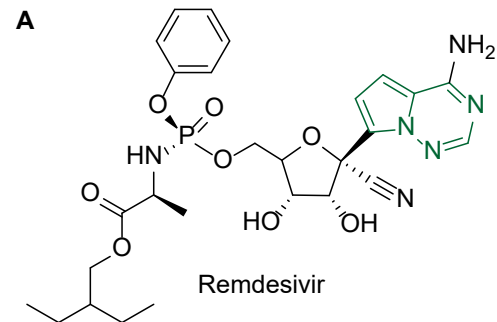<smiles>CCN(CC)CCCC(C)Nc1ccnc2cc(Cl)ccc12</smiles>

Chloroquine

Hydroxychloroquine

B<smiles>CC(N)(N)CNC(=O)C[C@H]1CC[C@]2(CC1)OO[C@@]1(O)C3CC4CC(C3)C2C1C4</smiles>

Arterolane

Synriam $^{\mathrm{TM}}$
C

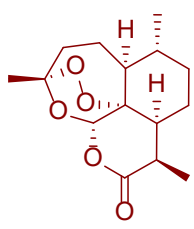

Artemisinin<smiles>C[C@@H]1CC[C@H]2[C@H](C)CC[C@H]3[C@@H](C)C(O)O[C@H](O1)[C@H]23</smiles>

Dihydroartemisinin

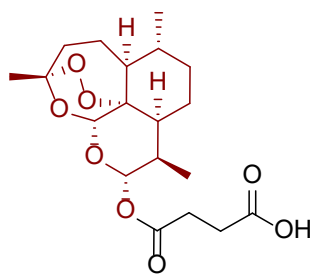

Artesunic acid

Figure 1. Structures of (A) antiviral Remdesivir and antimalarial/antiviral (Hydroxy)Chloroquine used as reference compounds in this study; (B) synthetic antimalarial and antiviral peroxide Arterolane; (C) Artemisinin (ARN, naturally occurring) and its semisynthetic derivatives Dihydroartemisinin (DHA) and Artesunic acid (ART).

\section{Results and Discussion}

\section{Chemistry}

Recently we reported the synthesis of different artesunic acidquinoline hybrid compounds, which showed highly improved potencies against chloroquine-resistant and multidrug-resistant $P$ falciparum strains and strongly suppressed parasitemia in experimental malaria. ${ }^{[18]}$ We initiated the present research by screening those hybrid compounds for the first time for their inhibitory activity against SARS-CoV-2. To our delight, artesunic acid-quinoline hybrid 1 displayed superior potency against SARSCoV-2 $\left(E_{50}=11 \pm 2.5 \mu \mathrm{M}\right)$, outperforming its parent compound artesunic acid $\left(\mathrm{EC}_{50}>50 \mu \mathrm{M}\right.$, Table 1, Figure 3). This remarkable result motivated us to further modify compound $\mathbf{1}$, using its alkyne linker und click reactions (Figure 2). This resulted in new artesunic acid-quinoline hybrids 2-7, which have also been investigated for their activity against SARS-CoV-2 in vitro. Hybrids 2-7 were synthesized, starting form 4,7-dichloroqunioline, which was transformed over two steps to alkyne precursor 14 after a literature-known procedure, earlier reported by our team ${ }^{[18]}$ From there on, triazole species 17-22 were synthesized via "click" copper-catalyzed alkyne azide cycloaddition reactions (CuAAC) in yields of $37-70 \%$. Triazoles $\mathbf{1 7 - 2 2}$ were prepared in a twophase solvent system using THF and water at room temperature under argon atmosphere. The chloroquinoline triazoles 17-22 underwent amide coupling reactions with EDCI and DMAP to form hybrid compounds 2-7 with artesunic acid. The reaction was performed in a mixture of DCM:THF due to poor solubility of the starting triazole compounds $\mathbf{1 7 - 2 2}$ in DCM. Corresponding hybrids 2-7 were obtained in $33-69 \%$ yields. 
Quinoline-adamantane hybrid 15 was synthesized from 7chloro- $\mathrm{N}$-(2-chloroethyl)quinolin-4-amine and 1-adamantylamine in presence of $\mathrm{Et}_{3} \mathrm{~N}$ in DMF under argon atmosphere. Hybrid 15 was isolated in $54 \%$ yield. The acidic starting compounds, containing a bridged 1,2,4,5-tetraoxane and tricyclic monoperoxide fragment for the synthesis of hybrids 8-13, were synthesized from corresponding $\beta$-diketones and $\beta, \delta^{\prime}$-triketones by their acid-catalyzed peroxidation in accordance with the known

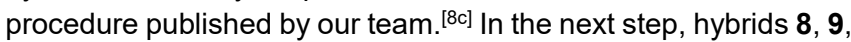
11 and 13 were synthesized via an amide coupling reaction between cyclic peroxide containing acid and an aminoquinoline under action of EDCl• $\mathrm{HCl} /$ DMAP system in DCM. Hybrids 8, 9, 11 and 132 were obtained in moderate to good yields (47-77\%) For an acid, which contains a tricyclic monoperoxide moiety, yield of target hybrids was $17-30 \%$ higher, compared to an acid containing a bridged 1,2,4,5-tetraoxane moiety. Hybrids 10 and 13 were synthetized via an esterification reaction between corresponding acids and an alcohol containing quinoline moiety under the action of a DCC / DMAP system in DCM, which gave yields for 10 and 13 of $47 \%$ and $67 \%$, respectively.
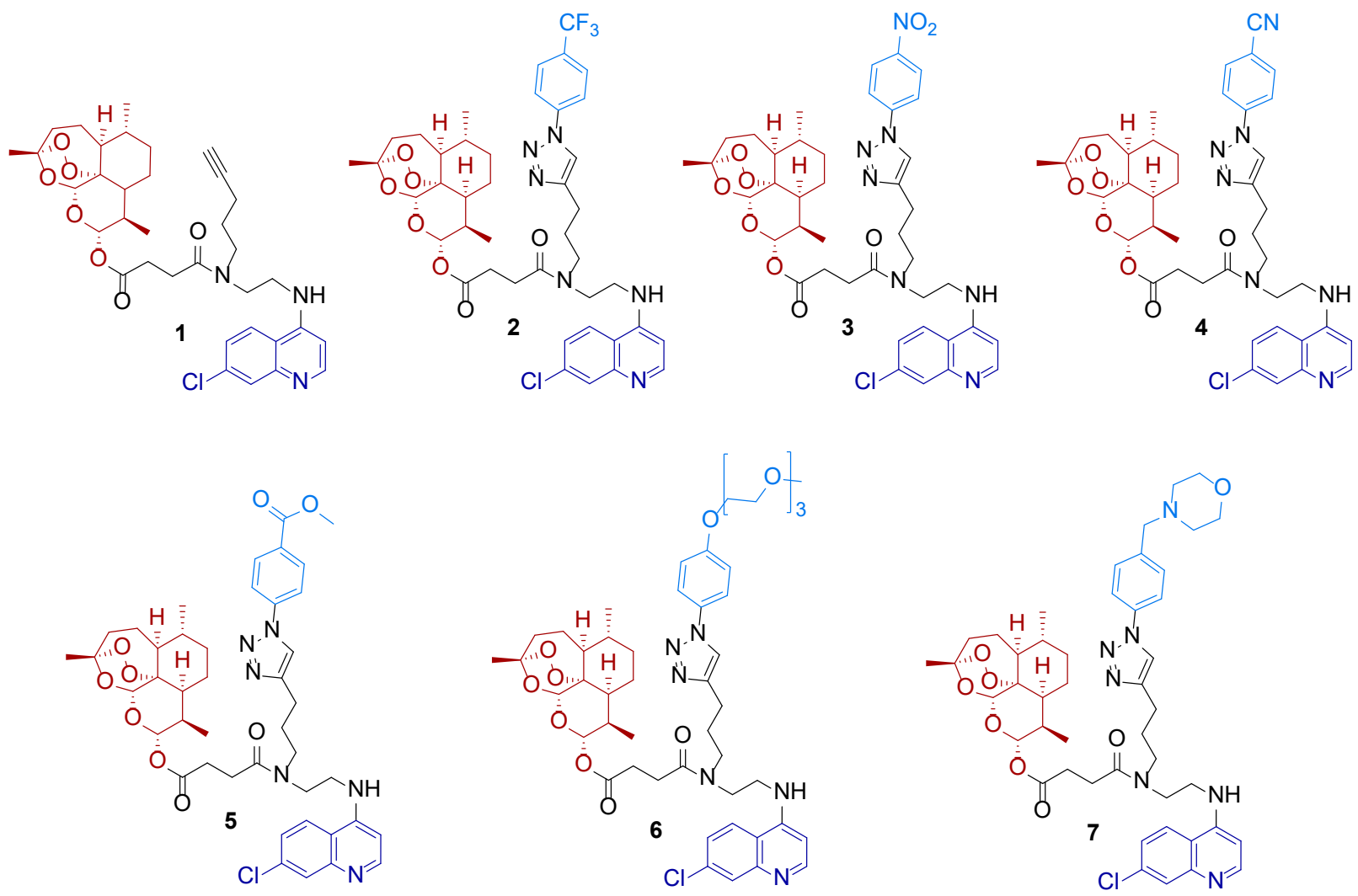<smiles>CC1(C)OOC1(C)OCCCC(=O)NCCNc1ccnc2cc(Cl)ccc12</smiles>

8<smiles>CC12CC3CC(CCC(=O)NCCCNc4ccnc5cc(Cl)ccc45)(OOC3(O)O1)O2</smiles>

12<smiles>CC1(O)OOC1(C)OC1(C)OC1(C)O</smiles>

9<smiles>CC12CC3CC(CCC(=O)OCCNc4ccnc5cc(Cl)ccc45)(OC1O3)C2(O)O</smiles>

13<smiles>CC1(C)OOC1(C)OCCC(=O)OCCNc1ccnc2cc(Cl)ccc12</smiles>

10<smiles>C#CCCCNCCNc1ccnc2cc(Cl)ccc12</smiles>

14

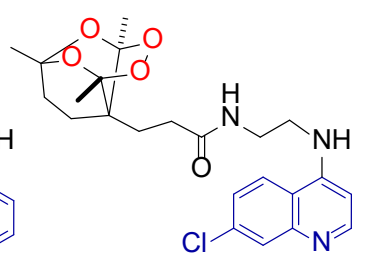

11<smiles>Clc1ccc2c(NCCNC34CC5CC(CC(C5)C3)C4)ccnc2c1</smiles>

15

Figure 2. Artemisinin- and quinoline-based compounds 1-15, designed for examination of their activity against SARS-CoV-2. 
A

R

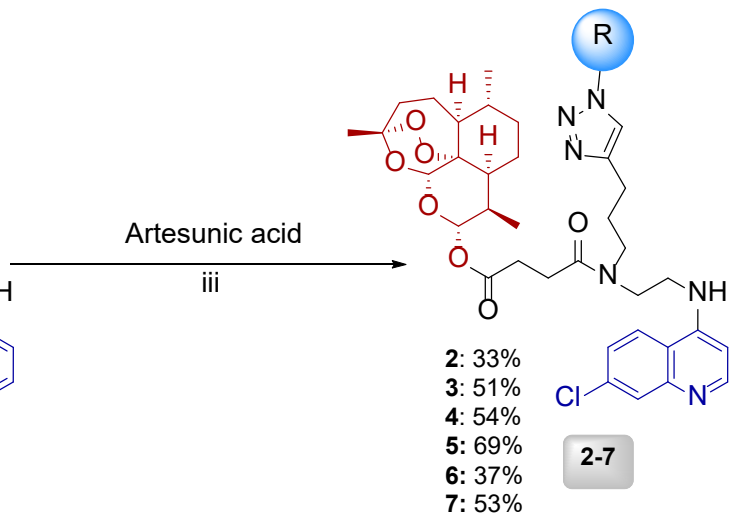

(14)

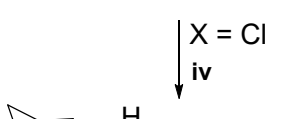

$\sqrt{\mathrm{N}} \mathrm{LNH}_{\mathrm{NH}}^{\mathrm{H}}$

(1)

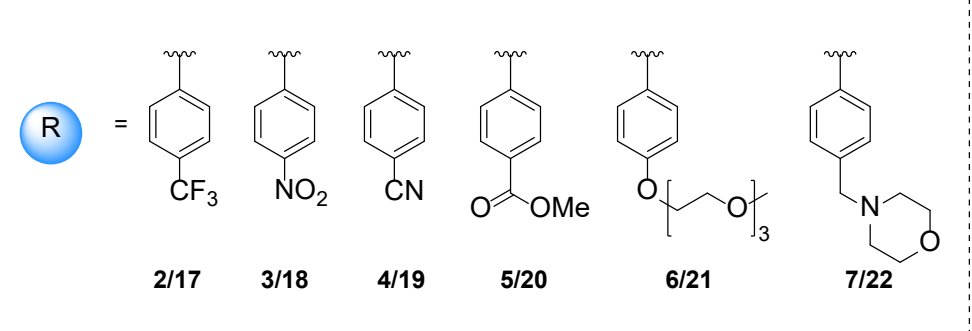

$1554 \%$

B

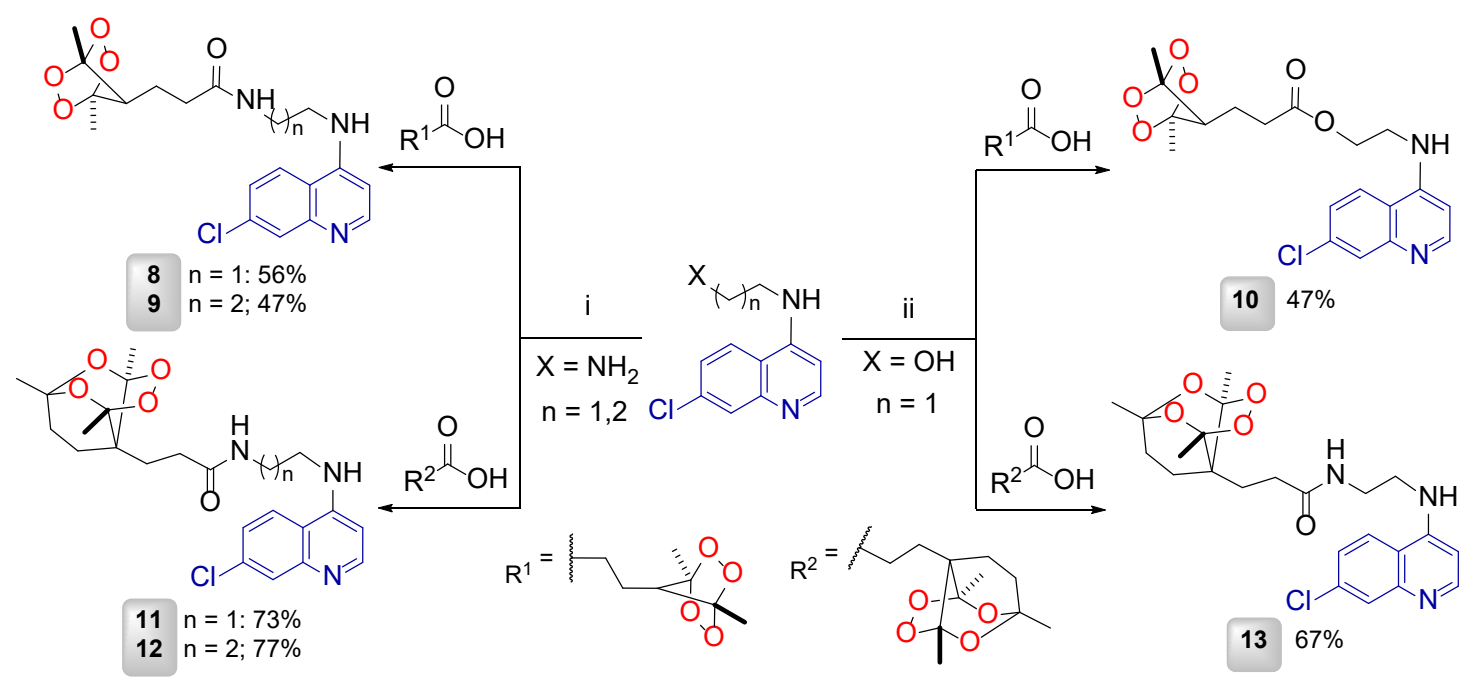

Scheme 1. (A) Synthesis of new artemisinin-based hybrids 2-7. i) Chloropent-1-yne, $\mathrm{K}_{2} \mathrm{CO}_{3}, \mathrm{CH}_{3} \mathrm{CN}, 115^{\circ} \mathrm{C}, 25 \mathrm{~h}$; ii) $\mathrm{CuSO}_{4} \cdot 5 \mathrm{H}_{2} \mathrm{O}(20 \mathrm{~mol} \%)$, sodium ascorbate $(40 \mathrm{~mol} \%)$, THF: $\mathrm{H}_{2} \mathrm{O}(1: 1)$, r.t., $2-3.5 \mathrm{~h}$; iii) EDCl $\cdot \mathrm{HCl}$, DMAP, DCM, $0{ }^{\circ} \mathrm{C}$ to r.t., o/n; iv) 1 -adamantylamine, Et ${ }_{3} \mathrm{~N}$, DMF, $140^{\circ} \mathrm{C}, 9$ h. (B) Synthesis of novel peroxide based hybrids 8-13: i) For 8, 9, 11 and 12: EDCl• $\mathrm{HCl}$, DMAP, DCM, $0{ }^{\circ} \mathrm{C}$ to r.t., o/n; ii) For 10 and 13: DCC, DMAP, DCM, $0{ }^{\circ} \mathrm{C}$ to r.t., o/n. 
Table 1. EC 50 values of hybrids 1-15 and of reference compounds artesunic acid (ART), chloroquine (CQ) and remdesivir, analyzed for anti-SARS-CoV-2 activities.

\begin{tabular}{|c|c|c|c|c|}
\hline Compound & $\mathrm{EC}_{50} \mathrm{CPE}[\mu \mathrm{M}]$ & $\mathrm{EC}_{50} \mathrm{IF}[\mu \mathrm{M}]$ & $\begin{array}{l}\mathrm{CC}_{50}[\mu \mathrm{M}] \\
\text { Vero E6 }\end{array}$ & SI \\
\hline 1 & $11 \pm 2.5$ & $\sim 14^{*}$ & $\sim 48^{*}$ & 4.4 \\
\hline 2 & $24 \pm 4.6$ & $12 \pm 7.0$ & $30 \pm 3.7$ & 1.3 \\
\hline 3 & $13 \pm 1.1$ & $33 \pm 15$ & $110 \pm 30$ & 8.5 \\
\hline 4 & $13 \pm 0.6$ & $81 \pm 23$ & $>100$ & $>7.7$ \\
\hline 5 & $19 \pm 2.4$ & $53 \pm 8.0$ & $>100$ & $>5.3$ \\
\hline 6 & $46 \pm 3.9$ & $>100$ & $>100$ & $>2.2$ \\
\hline 7 & $7.8 \pm 3.0$ & $>16$ & $25 \pm 2.9$ & 3.2 \\
\hline 8 & $25 \pm 1.4$ & $\sim 90^{*}$ & $\sim 50^{*}$ & 2.0 \\
\hline 9 & $13 \pm 0.3$ & $13 \pm 3.1$ & $28 \pm 2.9$ & 2.2 \\
\hline 10 & $11 \pm 0.3$ & $30 \pm 5.9$ & $\sim 37^{*}$ & 3.4 \\
\hline 11 & $73 \pm 5.3$ & $>100$ & $>100$ & $>1.4$ \\
\hline 12 & $44 \pm 3.2$ & $59 \pm 8.1$ & $>100$ & $>2.3$ \\
\hline 13 & $48 \pm 4.0$ & $72 \pm 22$ & $>100$ & $>2.1$ \\
\hline 14 & $6.4 \pm 0.2$ & $9.5 \pm 1.6$ & $\sim 60^{*}$ & 9.4 \\
\hline 15 & $1.5 \pm 0.1$ & $>2.6$ & $5.9 \pm 1.6$ & 3.9 \\
\hline artesunic acid & $>50$ & n.d. & $>50$ & - \\
\hline chloroquine & $3.8 \pm 0.5$ & $1.3 \pm 0.3$ & $\sim 27^{*}$ & 7.1 \\
\hline remdesivir & $4 \pm 0.2$ & $0.63 \pm 0.06$ & $>50$ & $>13$ \\
\hline
\end{tabular}

*Estimate, standard deviation could not be determined due to incomplete $95 \%$ confidence interval; n.d. = not determined;

$\mathrm{SI}$ (selectivity index) $=\mathrm{EC}_{50} \mathrm{CPE} / \mathrm{CC}_{50}$ Vero E6

\section{Anti-SARS-CoV-2 Activity}

The in vitro anti-SARS-CoV-2 potency of novel hybrid drugs was confirmed using Vero E6 cells. The cytotoxicity of all hybrid compounds towards Vero E6 cells was assessed, too, to ensure that the antiviral effects were not caused by toxicity. These tests confirmed, that hybrid compounds 1-15 inhibit replication of SARS-CoV-2 viruses at levels at which there is only low or no toxicity to the cells at all (Figures 3 and 4, Table 1).

All new artesunic acid-containing hybrid compounds 2-7 show activity against SARS-CoV-2 (EC ( $_{0}$ values $\left.7.8-46 \mu \mathrm{M}\right)$ and low or no toxicity at the effective concentrations, indicated by $\mathrm{SI}$ (selectivity index) values up to 8.5. The morpholine-containing derivative 7 shows the highest activity $\left(\mathrm{EC}_{50}=7.8 \pm 3.0 \mu \mathrm{M}\right)$ with a SI value of 3.2. The morpholine moiety may improve the activity against SARS-CoV-2 due to its basic nature. ${ }^{[19]}$
Among quinoline-based hybrids 8-15, compound 15 was the most active $\left(\mathrm{EC}_{50}=1.5 \pm 0.5 \mu \mathrm{M}\right.$ and $\mathrm{SI}=3.9$, see Table 1 and Figure 4).

Replacement of the adamantane fragment in 15 by 1 pentyne (see compound 14) led to a decrease in activity, but to an increase in $\mathrm{SI}\left(\mathrm{EC}_{50}\right.$ and $\mathrm{SI}$ are $6.4 \pm 0.2 \mu \mathrm{M}$ and 9.4, respectively). In the case of synthetic peroxide-containing hybrids 8-13, compounds 8-10 with a 1,2,4,5-tetraoxane moiety were several times more active than compounds $11-13$, containing a tricyclic monoperoxide fragment. From the structural point of view, compounds with an ester group, like 10 and 13, or with a chain of three carbon atoms between the amino group of quinoline and amido group such as in case of $\mathbf{9}$ and 12, are more promising as components for the development of hybrids against SARS-CoV2. Most active synthetic peroxide-quinoline hybrid was $10\left(E C_{50}\right.$ and $\mathrm{SI}$ are $11.5 \pm 0.3 \mu \mathrm{M}$ and 3.4 , respectively). 
A

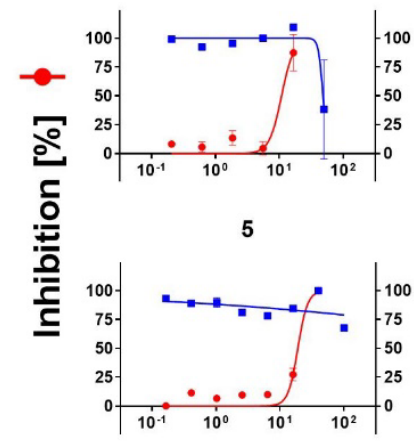

2

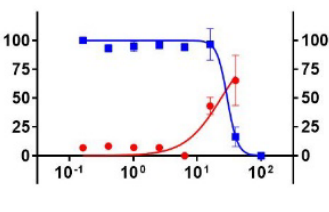

6

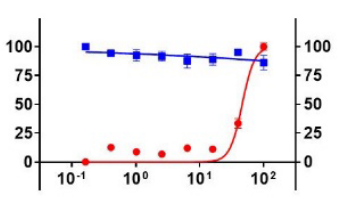

3

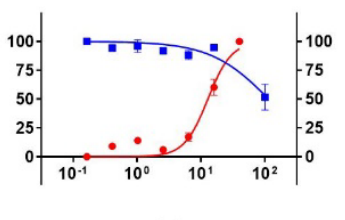

7

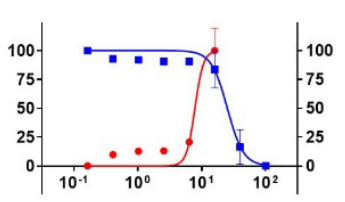

4

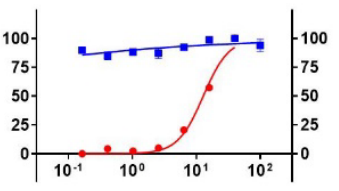

artesunic acid

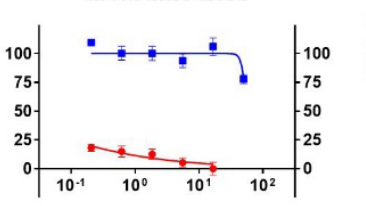

\section{Compound concentration $[\mu \mathrm{M}]$}

B

1

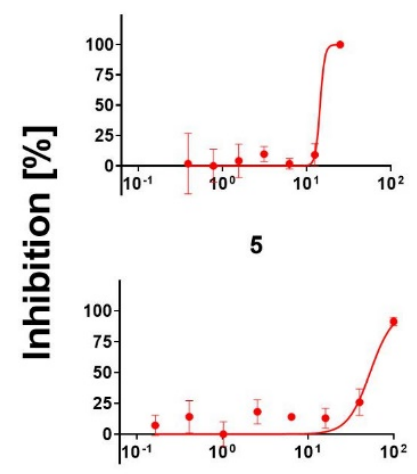

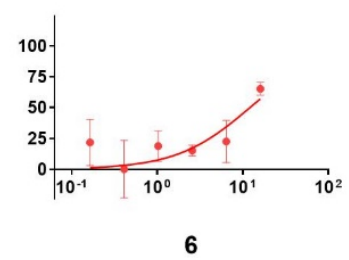

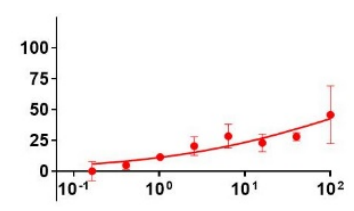

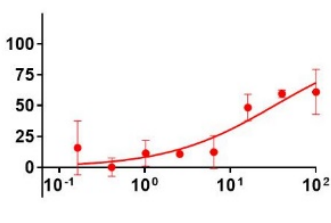

7

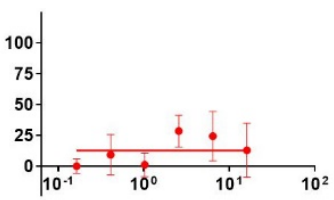

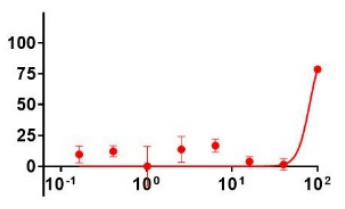

\section{Compound concentration $[\mu \mathrm{M}]$}

Figure 3. Dose-response curves of SARS-CoV-2 inhibition by different doses of artemisinin hybrids 1-7 and artesunic acid. (A) Graphical representation of CPE-based assay. Vero E6 cells were infected with SARS-CoV-2 at an MOI of 0.04 for $72 \mathrm{~h}$ and the inhibition of virus-induced cytopathic effect by 2.5 fold serial dilution of compounds 1-7 was determined by XTT assay (red circle). Same dilution of compounds 1-7 without SARS-CoV-2 were used to determine cell cytotoxicity (blue squares). (B) Graphical representation of immunofluorescence assay. Vero E6 cells were infected with SARS-CoV-2 at an MOI of 0.04 for $72 \mathrm{~h}$ and the inhibition of virus replication was determined by anti-SARS-CoV-2 nucleoprotein antibody. $\mathrm{MOI}=$ multiplicities of infection. 
A

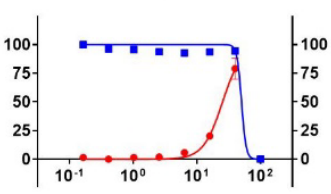

12

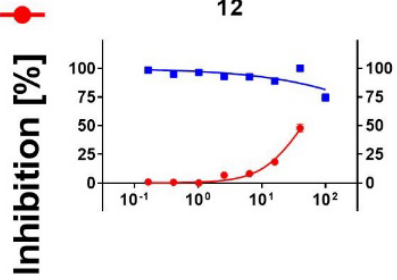

chloroquine

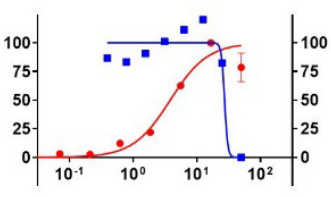

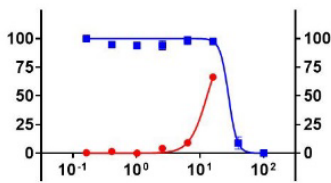

13

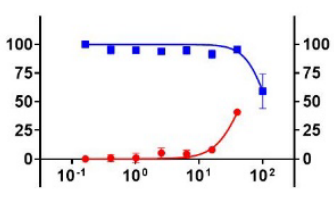

remdesivir

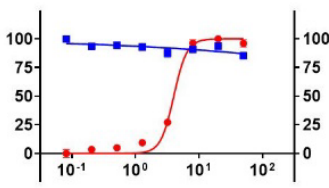

Compound concentration $[\mu \mathrm{M}]$
10

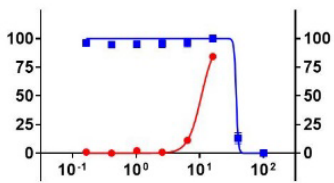

14

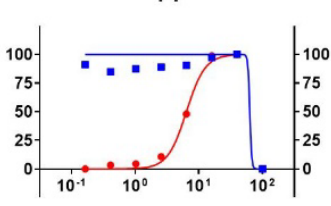

11

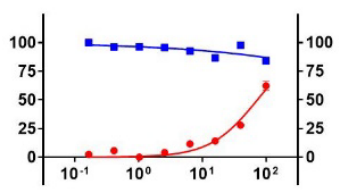

15

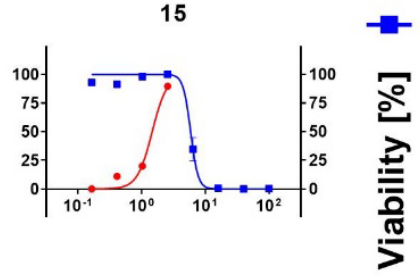

B

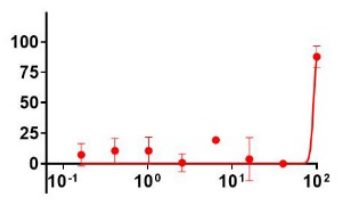

12

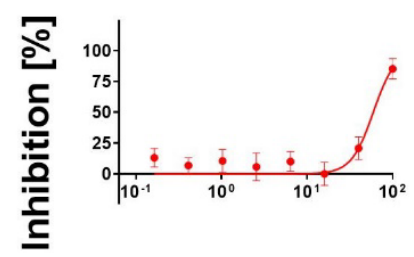

chloroquine

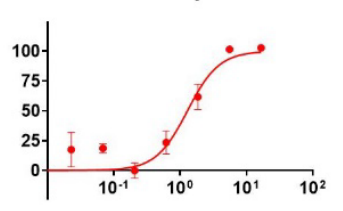

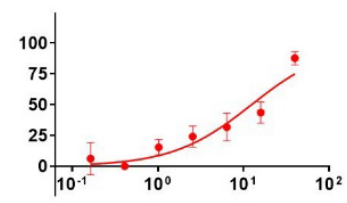

13

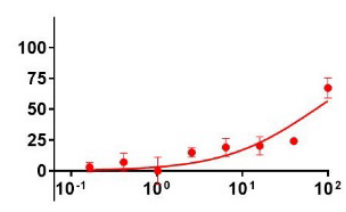

remdesivir

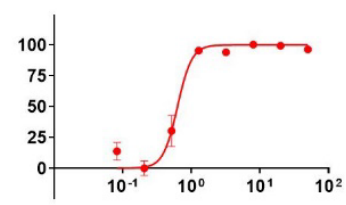

10

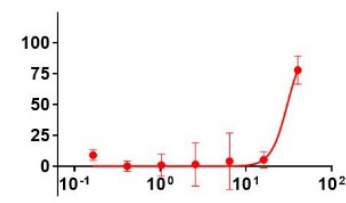

14

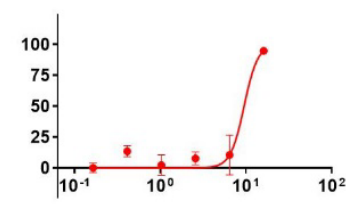

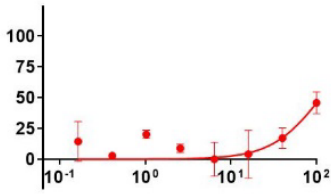

15

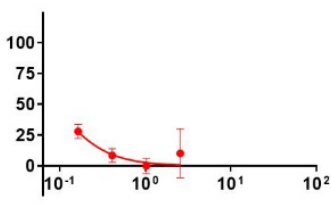

\section{Compound concentration $[\mu \mathrm{M}]$}

Figure 4. Dose-response curves of SARS-CoV-2 inhibition by different doses of quinoline hybrids 8-15, chloroquine, and remdesivir control. (A) Graphical representation of CPE-based assay. Vero E6 cells were infected with SARS-CoV-2 at an MOI of 0.04 for $72 \mathrm{~h}$ and the inhibition of virus-induced cytopathic effect by 2.5 fold serial dilution of compounds 8-15 was determined by XTT assay (red circle). Same dilution of compounds 8-15 without SARS-CoV-2 were used to determine cell cytotoxicity (blue squares). (B) Graphical representation of immunofluorescence assay. Vero E6 cells were infected with SARS-CoV-2 at an MOI of 0.04 for $72 \mathrm{~h}$ and the inhibition of virus replication was determined by anti-SARS-CoV-2 nucleoprotein antibody. MOI = multiplicities of infection. 


\section{Molecular modeling}

Further lead optimization and design of novel inhibitors of SARSCoV-2 replication require knowledge about molecular targets and binding patterns of quinoline-based hybrids (chloroquine-like ligands). Based on crystallographic data collection deposited in the Protein Data Bank (PDB), possible quinoline binding sites were found in SARS-CoV-2 main protease and spike glycoprotein (see Supporting Information). A molecular docking approach was used for preliminary estimation of ligand binding in each possible binding site and results were subjected to protein-ligand structure refinement by MD simulation. ${ }^{[20]}$ According to molecular modeling, SARS-CoV-2 main protease $\left(\mathrm{M}^{\text {pro }}\right)$ was identified as the most probable binding partner for quinoline-based compounds (Figure 5). Hydrogen bonds between the quinoline moiety and His163, hydrogen bonds with Asn142, and a salt bridge with Glu166 are most important for high-affinity binding.

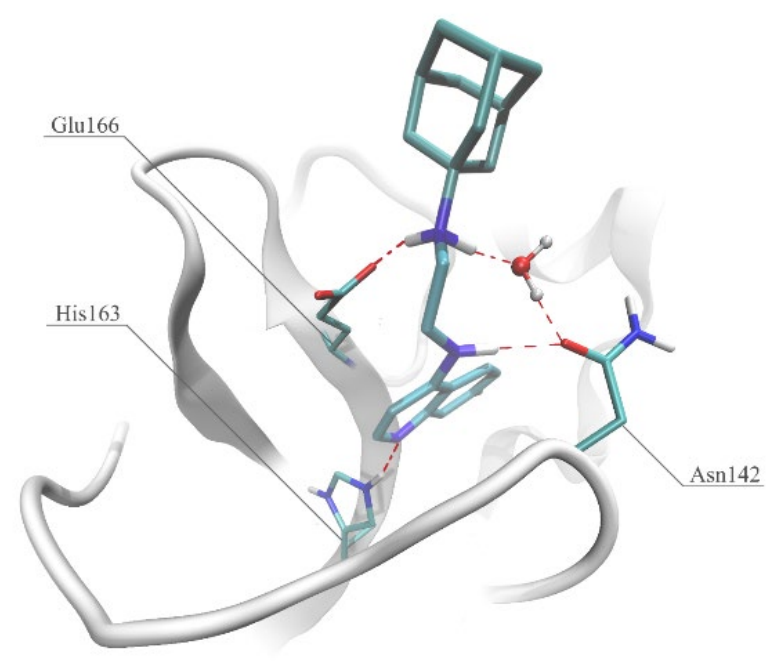

Figure 5. Essential interactions of quinolone-adamantane derivates with SARS-CoV-2 main protease $\left(\mathrm{M}^{\mathrm{pro}}\right)$ identified by molecular modelling. A representative binding pose from molecular dynamics simulations for ligand $\mathbf{1 5}$ is shown.

The found binding site is consistent with experimental data (Supporting Information, Figure S3), as well as with results of molecular modeling studies. ${ }^{[21]}$ High observed experimental activity of positively charged compounds can be explained by taking into account their electrostatic interaction with Glu166 (Figure 5).

\section{Conclusions}

In summary, these study reinforce our hypothesis that artemisinin and quinoline hybrid compounds could be effective as a COVID19 treatment. We synthesized and explored the in vitro antiSARS-CoV-2 activities of fifteen artemisinin- and quinolinecontaining hybrid compounds 1-15. All artemisinin-based hybrids 1-7 display superior potency against SARS-CoV-2 $\left(\mathrm{EC}_{50}\right.$ values $7.8-46 \mu \mathrm{M})$ outperforming artesunic acid. The most active artesunic acid-derived hybrid $7\left(E_{50}=7.8 \mu \mathrm{M}\right)$ is also significantly more potent in vitro than its parent compound artesunic acid $\left(E_{50}>50 \mu \mathrm{M}\right)$ and shows low cytotoxic effects on benchmark Vero E6 cells. Notably, also synthetic peroxide-based hybrids 8-13 were remarkably potent against SARS-CoV-2. Most active synthetic peroxide-quinoline hybrid was $10 \quad\left(\mathrm{EC}_{50}=\right.$ $11.5 \mu \mathrm{M})$. Among quinoline-based new compounds, quinolineadamantane $15\left(E_{50}=1.5 \mu \mathrm{M}\right)$ is the most efficient in vitro, outperforming chloroquine $\left(E_{50}=3.8 \mu \mathrm{M}\right)$ and remdesivir $\left(E_{50}\right.$ $=4.0 \mu \mathrm{M}$ ), used as reference drugs. These promising results further underline the high potential of the hybridization concept for further investigations and hybrid-based drug design of efficient antiviral agents to treat SARS-CoV-2 infections.

\section{Acknowledgements}

We gratefully acknowledge financial support from the Deutsche Forschungsgemeinschaft (DFG, Grant TS $87 / 23-1$ for S.B.T.) and financial support from the Russian Science Foundation (Grant No. 2143-04417 for I.A.Y. and A.O.T.). Generous support by the DFG (Gottfried Wilhelm Leibniz award to L.A.) is gratefully acknowledged. We also thank the Interdisciplinary Center for Molecular Materials (ICMM), the Graduate School Molecular Science (GSMS), as well as the Emerging Fields Initiative (EFI) "Chemistry in Live Cells" supported by Friedrich-Alexander-Universität Erlangen-Nürnberg for support and funding. Financial support by the German Academic Exchange Service (DAAD) through a doctoral research fellowship for A.Ç. is also gratefully acknowledged.

[1] WHO, in situation reports, Vol. 180, World Health Organization, 2020.

[2] M. Wang, R. Cao, L. Zhang, X. Yang, J. Liu, M. Xu, Z. Shi, Z. Hu, W. Zhong, G. Xiao, Cell Res. 2020, 30, 269-271.

[3] a) Y. Jiang, D. Chen, D. Cai, Y. Yi, S. Jiang, J. Med. Virol. 2021, 93, 1171-1174; b) B. Young, T. T. Tan, Y. S. Leo Lancet Infect. Dis. 2021, 21, 20-21; c) G. Kokic, H. S. Hillen, D. Tegunov, C. Dienemann, F. Seitz, J. Schmitzova, L. Farnung, A. Siewert, C. Höbartner, P. Cramer, Nat. Commun. 2021, 12, 279-285.

[4] S. D'Alessandro, D. Scaccabarozzi, L. Signorini, F. Perego, D. P. Ilboudo, P. Ferrante, S. Delbue, Microorganisms 2020, 8.

[5] a) D. Plantone, T. Koudriavtseva, Clin. Drug Investig. 2018 38, 653-671; b) Y. Chen, M.-X. Li, G.-D. Lu, H.-M. Shen, J. Zhou, Int. J. Biol. Sci. 2021, 17, 1538-1546.

[6] a) A. Giacomelli, G. Pagani, A. L. Ridolfo, L. Oreni, F. Conti, L. Pezzati, L. Bradanini, G. Casalini, C. Bassoli, V. Morena S. Passerini, G. Rizzardini, C. Cogliati, E. Ceriani, R. Colombo, S. Rusconi, C. Gervasoni, D. Cattaneo, S. Antinori, M. Galli, J. Med. Virol. 2021, 93, 1421-1427; b) P De Luca, A. Scarpa, E. De Bonis, M. Cavaliere, P. Viola, F. M. Gioacchini, M. Ralli, C. Ettore, C. Claudia, Am. J. Otolaryngol. 2021, 42, 102640-102652.

[7] a) X. Wang, Y. Dong, S. Wittlin, S. A. Charman, F. C. K Chiu, J. Chollet, K. Katneni, J. Mannila, J. Morizzi, E. Ryan, C. Scheurer, J. Steuten, J. Santo Tomas, C. Snyder, J. L. Vennerstrom, J. Med. Chem. 2013, 56, 2547-2555; b) C. Giannangelo, F. J. I. Fowkes, J. A. Simpson, S. A. Charman, D. J. Creek, Trends in Parasitol. 2019, 35, 529-543; c) K. Ingram, I. A. Yaremenko, I. B. Krylov, L. Hofer, A. O. Terent'ev, J. Keiser, J. Med. Chem. 2012, 55, 8700-8711; d) J. Keiser, K. Ingram, M. Vargas, J. Chollet, X. Wang, Y. Dong, J. L. Vennerstrom, Antimicrob. Agents Chemother. 2012, 56, 1090; e) V. Vil', I. Yaremenko, A. Ilovaisky, A. Terent'ev, Molecules 2017, 22, 1881.

[8] a) R. P. Abrams, W. L. Carroll, K. A. Woerpel, ACS Chem. Biol. 2016, 11, 1305-1312; b) D. Chaturvedi, A. Goswami, P. Pratim Saikia, N. C. Barua, P. G. Rao, Chem. Soc. Rev. 2010, 39, 435-454; c) P. Coghi, I. A. Yaremenko, P. Prommana, P. S. Radulov, M. A. Syroeshkin, Y. J. Wu, J. Y. Gao, F. M. Gordillo, S. Mok, V. K. W. Wong, C. Uthaipibull, A. O. Terent'ev, ChemMedChem 2018, 13, 902-908; d) A. Dwivedi, A. Mazumder, L. du Plessis, J. L. du Preez, R. K. Haynes, J. du Plessis, Nanomed.: Nanotechnol. Biol. Med. 2015, 11, 2041-2050; e) I. A. Yaremenko, M. A. Syroeshkin, D. O. Levitsky, F. Fleury, A. O. Terent'ev, Med. Chem. Res. 2017, 26, 170-179; f) A. A. 
Alagbala, A. J. McRiner, K. Borstnik, T. Labonte, W. Chang, J. G. D'Angelo, G. H. Posner, B. A. Foster, J. Med. Chem. 2006, 49, 7836-7842; g) D. M. Rubush, M. A. Morges, B. J. Rose, D. H. Thamm, T. Rovis, J. Am. Chem. Soc. 2012 134, 13554-13557; h) M. B. Chaudhari, S. Moorthy, S. Patil, G. S. Bisht, H. Mohamed, S. Basu, B. Gnanaprakasam, J. Org. Chem. 2018, 83, 1358-1368; i) F. Gao, Z. Sun, F. Kong J. Xiao, Eur. J. Med. Chem. 2020, 188, 112044-112063; j) V. A. Vil', I. A. Yaremenko, D. I. Fomenkov, D. O. Levitsky, F. Fleury, A. O. Terent'ev, Chem. Het. Compd. 2020, 56 , 722-726; k) I. A. Yaremenko, P. Coghi, P. Prommana, C Qu, P. S. Radulov, Y. Qu, Y. Y. Belyakova, E. Zanforlin, V. A. Kokorekin, Y. Y. J. Wu, F. Fleury, C. Uthaipibull, V. K. W Wong, A. O. Terent'ev, ChemMedChem 2020, 15, 11181127.

[9] a) I. A. Yaremenko, M. Y. Syromyatnikov, P. S. Radulov, Y. Y. Belyakova, D. I. Fomenkov, V. N. Popov, A. O. Terent'ev, Molecules 2020, 25; b) I. A. Yaremenko, P. S. Radulov, Y. Y. Belyakova, A. A. Demina, D. I. Fomenkov, D. V Barsukov, I. R. Subbotina, F. Fleury, A. O. Terent'ev, Chem. Eur. J. 2020, 26, 4734-4751.

[10] a) S. Chaudhary, V. Sharma, P. K. Jaiswal, A. N. Gaikwad, S. K. Sinha, S. K. Puri, A. Sharon, P. R. Maulik, V. Chaturvedi, Org. Lett. 2015, 17, 4948-4951; b) M. J. Miller, A. J. Walz, H. Zhu, C. Wu, G. Moraski, U. Möllmann, E. M. Tristani, A. L. Crumbliss, M. T. Ferdig, L. Checkley, R. L. Edwards, H. I. Boshoff, J. Am. Chem. Soc. 2011, 133 2076-2079; c) F.-W. Zhou, H.-S. Lei, L. Fan, L. Jiang, J. Liu, X.-M. Peng, X.-R. Xu, L. Chen, C.-H. Zhou, Y.-Y. Zou, C. P. Liu, Z.-Q. He, D.-C. Yang, Bioorg. Med. Chem. Lett. 2014 24, $1912-1917$.

[11] a) S. Chou, G. Marousek, S. Auerochs, T. Stamminger, J. Milbradt, M. Marschall, Antivir. Res. 2011, 92, 364-368; b) T. Efferth, M. R. Romero, D. G. Wolf, T. Stamminger, J. J. G. Marin, M. Marschall, Arch. Clin. Infect. Dis. 2008, 47, 804-811; c) T. Efferth, Biotechnol. Adv. 2018, 36, 17301737; d) C. Reiter, T. Fröhlich, L. Gruber, C. Hutterer, M. Marschall, C. Voigtlander, O. Friedrich, B. Kappes, T Efferth, S. B. Tsogoeva, Bioorg. Med. Chem. 2015, 23 , $5452-5458$.

[12] a) M. A. Biamonte, J. Wanner, K. G. Le Roch, Bioorg. Med. Chem. Lett. 2013, 23, 2829-2843; b) X. Wang, Y. Dong, S. Wittlin, S. A. Charman, F. C. K. Chiu, J. Chollet, K. Katneni, J. Mannila, J. Morizzi, E. Ryan, C. Scheurer, J. Steuten, J. Santo Tomas, C. Snyder, J. L. Vennerstrom, J. Med. Chem. 2013, 56, 2547-2555; c) S. D. Fontaine, B. Spangler, J. Gut, E. M. W. Lauterwasser, P. J. Rosenthal, A. R. Renslo, ChemMedChem 2015, 10, 47-51.

[13] a) A. K. Ghosh, H. Miller, K. Knox, M. Kundu, K. J. Henrickson, R. Arav-Boger, ACS Infect. Dis. 2021, 7, 19851995; b) Y. Yang, M. S. Islam, J. Wang, Y. Li, X. Chen, Int. J. Biol. Sci. 2020, 16, 1708-1717.

[14] C. Nie, J. Trimpert, S. Moon, R. Haag, K. Gilmore, B. B. Kaufer, P. H. Seeberger, bioRxiv 2021 2021.2002.2014.431122.

[15] a) M. Gendrot, I. Duflot, M. Boxberger, O. Delandre, P. Jardot, M. Le Bideau, J. Andreani, I. Fonta, J. Mosnier, C. Rolland, S. Hutter, B. La Scola, B. Pradines, Int. J. Infect. Dis. 2020, 99, 437-440; b) M. Izoulet, 2020, http://dx.doi.org/10.2139/ssrn.3575899.

[16] a) R. Cao, H. Hu, Y. Li, X. Wang, M. Xu, J. Liu, H. Zhang, Y. Yan, L. Zhao, W. Li, T. Zhang, D. Xiao, X. Guo, Y. Li, J. Yang, Z. Hu, M. Wang, W. Zhong, ACS Infect. Dis. 2020, 6, 2524-2531; b) Y. Zhou, K. Gilmore, S. Ramirez, E. Settels K. A. Gammeltoft, L. V. Pham, U. Fahnøe, S. Feng, A Offersgaard, J. Trimpert, J. Bukh, K. Osterrieder, J. M. Gottwein, P. H. Seeberger, Sci. Rep. 2021, 11, 1457114584.

[17] a) L. F. Tietze, H. P. Bell, S. Chandrasekhar, Angew. Chem. Int. Ed. 2003, 42, 3996-4028; b) B. Meunier, Acc. Chem. Res. 2008, 41, 69-77; c) S. B. Tsogoeva, Mini Rev. Med. Chem. 2010, 10, 773-793; d) G. Mehta, V. Singh, Chem. Soc. Rev. 2002, 31, 324-334; e) M. d. Oliveira Pedrosa, R. M. Duarte da Cruz, J. d. Oliveira Viana, R. O. de Moura, H M. Ishiki, J. M. Barbosa Filho, M. F. F. M. Diniz, M. T. Scotti, L. Scotti, F. J. Bezerra Mendonca, Curr. Top. Med. Chem. 2017, 17, 1044-1079; f) H. M. Sampath Kumar, L.
Herrmann, S. B. Tsogoeva, Bioorg. Med. Chem. Lett. 2020, 30, 127514-127528.

[18] A. Capci, M. M. Lorion, H. Wang, N. Simon, M. Leidenberger, M. C. Borges Silva, D. R. M. Moreira, Y. Zhu, Y. Meng, J. Y. Chen, Y. M. Lee, O. Friedrich, B. Kappes, J. Wang, L. Ackermann, S. B. Tsogoeva, Angew. Chem. Int. Ed. 2019, 58, 13066-13079.

[19] a) E. A. Rekka, P. N. Kourounakis, Curr. Med. Chem. 2010, 17, 3422-3430; b) A. P. Kourounakis, D. Xanthopoulos, A Tzara, Med. Res. Rev. 2020, 40, 709-752.

[20] M. Sagnou, F. N. Novikov, E. S. Ivanova, P. Alexiou, V. S Stroylov, I. Y. Titov, V. V. Tatarskiy, M. S. Vagida, M. Pelecanou, A. A. Shtil, G. G. Chilov, Eur. J. Med. Chem. 2020, 198.

[21] a) J. Osipiuk, C. Tesar, M. Endres, V. Lisnyak, S. Maki, C. Taylor, Y. Zhang, Z. Zhou, S. Azizi, K. Jones, R. Kathayat, S. Snyder, B. Dickinson, A. Joachimiak, 2020, p. DOI:10.2210/pdb2217krx/pdb; b) J. Osipiuk, S. A. Azizi, S. Dvorkin, M. Endres, R. Jedrzejczak, K. A. Jones, S. Kang R. S. Kathayat, Y. Kim, V. G. Lisnyak, S. L. Maki, V. Nicolaescu, C. A. Taylor, C. Tesar, Y. A. Zhang, Z. Y. Zhou, G. Randall, K. Michalska, S. A. Snyder, B. C. Dickinson, A Joachimiak, Nat. Commun. 2021, 12. 